\title{
High-fat diet and streptozotocin in the induction of type 2 diabetes mellitus: a new proposal
}

\author{
DIEGO A. DE MAGALHÃES, WILLIAN T. KUME, FRANCYELE S. CORREIA, THAÍS S. QUEIROZ, EDGAR \\ W. ALLEBRANDT NETO, MAÍSA P. DOS SANTOS, NAIR H. KAWASHITA and SUÉLEM A. DE FRANÇA
}

Universidade Federal de Mato Grosso, Instituto de Ciências Exatas e da Terra, Departamento de Química, Laboratório de Bioquímica Pesquisa, Av. Fernando Correa da Costa, 2367, Boa Esperança, 78060-900 Cuiabá, MT, Brazil

Manuscript received on March 26, 2018; accepted for publication on June 6, 2018

\begin{abstract}
How to cite: MAGALHÃES DA, KUME WT, CORREIA FS, QUEIROZ TS, ALLEBRANDT NETO EW, SANTOS MP, KAWASHITA NH AND FRANÇA SA. 2019. High-fat diet and streptozotocin in the induction of type 2 diabetes mellitus: a new proposal. An Acad Bras Cienc 91: e20180314. DOI 10.1590/0001-3765201920180314.
\end{abstract}

\begin{abstract}
Our objective was to establish a diabetes mellitus type 2 (DM2) model in rats using a highfat diet and streptozotocin (HF-STZ). Male Wistar rats (240-250g) were divided into a control group (commercial feed), and HF-STZ group, (66.5\%-commercial feed, 13.5\%-lard, and 20\%-sugar). STZ $\left(40 \mathrm{mg} / \mathrm{kg}\right.$ i.p.) or vehicle was administered on the $13^{\text {th }}$ day. An oral glucose tolerance test (OGTT) was performed (2.5mg of glucose $/ \mathrm{kg}$ v.o.) on both groups. After 39 days of treatment, blood and tissue samples were collected for analyses. The weight gain after STZ administration was lower in the HF-STZ group than in the control group with reductions in muscle mass and adipose tissue. The HF-STZ group showed hyperglycemia after STZ administration (glucose on day 39: HF-STZ: $499 \pm 60$; control: $134 \pm 9 \mathrm{mg}$ / dL). Serum glucagon was $23 \%$ lower, and insulin levels were unaltered. The HOMA index was 4-times higher in the HF-STZ. The HF-STZ group showed increased post-prandial (330\%) and fasting (125\%) triglycerides, and while glycogen content in the liver and muscles decreased (70-80\%). The area under the curve (OGTT) was $282 \%$ higher in the HF-STZ group. The combination of high-fat diet with STZ (i.p) generated rats with hyperglycemia associated with hypertriglyceridemia and introduced many other alterations present in human DM2.
\end{abstract}

Key words: diabetes mellitus type 2 model, high-fat diet, streptozotocin, rats.

\section{INTRODUCTION}

Diabetes mellitus is a chronic endocrine disorder characterized by defects in the production of insulin by the pancreatic $\beta$ cells or its action in peripheral tissues, which cause metabolic changes and lead to increase in blood glucose levels. It is considered a worldwide public health problem and contributes to various complications, such as vision loss,

Correspondence to: Suélem Aparecida de França

E-mail: suafranca@hotmail.com

ORCid: http://orcid.org/0000-0002-3829-8530 bacterial and viral infections, emotional trauma, chronic renal failure, and vascular complications, which may progress to a state of disability or death (Sheetz 2002, Kawahito et al. 2009).

Diabetes mellitus is classified as type 1 (DM1) or type 2 (DM2). DM1 is when the pancreas stops producing the hormone insulin or produces it in very small amounts due to the destruction of $\beta$ cells (Piya et al. 2010). DM2 is the most common type and represents about $90 \%$ of cases of diabetes (Montani et al. 2016). In addition to genetic predisposition, its occurrence 
is due to factors such as increased longevity of the population, malnutrition (hypercaloric food with low nutritional value), physical inactivity, obesity, and aging (Defronzo and Abdul-ghani 2011). DM2 is commonly characterized by hyperglycemia, insulin resistance, and insulin deficiency (Maitra and Abbas 2005).

Experimental models in animals are used to study various aspects related to the disease, such as its symptoms, evolution, and complications. They have also been used in pharmacological tests in the search for more effective drugs and treatments. The diabetes model most often used involves the administration of a single high dose of streptozotocin (STZ) or alloxan (ALX) to adult animals, which leads to the destruction of pancreatic $\beta$ cells and causes hyperglycemia as a direct consequence of deficient insulin production (Correia-Santos et al. 2012). Although some symptoms of diabetes can be obtained experimentally using diets with high amounts of lipids and sugars (Arulmozhi et al. 2004), the use of experimental models with similarity to human DM2 is still problematic. Studies have shown that mice fed a high-fat (HF) diet develop symptoms related to DM2, such as insulin resistance and hyperinsulinemia, but not hyperglycemia (Srinivasan et al. 2005). On the other hand, hyperlipidemic diets associated with a dose of STZ have shown positive results in establishing DM2, but there are differences regarding the composition of the diet, the dose of STZ to be administered, and the species and the age of animal (Correia-Santos et al. 2012, Atanasovska et al. 2014).

Experimental models should also be easy to execute and have low cost. Based on this information, we present an experimental model for diabetes using adult male Wistar rats. The rats were fed a commercial diet recommended for rodents that was enriched with animal fat (lard) and sugar (to increase the caloric value), along with the administration of STZ i.p. The
STZ was administered at a dose slightly lower than that usually used to establish DM1. We hypothesized that the animals would show the main symptoms observed in DM2 in humans, such as hyperglycemia, insulin resistance, altered lipid profile, and other effects of hyperglycemia (such as glycosuria, polyuria, and thirst). Due to the lack of insulin action, the animals also should present lower weight gain, reduced muscle mass, and reduced fat and glycogen deposits at the end of the treatment period.

\section{MATERIALS AND METHODS}

\section{ANIMALS AND TREATMENT}

Male Wistar rats weighing approximately 240-250 $\mathrm{g}$ (10 weeks old) were randomly divided into two groups. The control group was fed commercial feed (Labina), and the HF-STZ group was fed a diet with $66.5 \%$ commercial feed, $13.5 \%$ lard, and $20 \%$ sugar. The chemical composition of the Labina feed and HF diet is described in Table Ia, b. The HF diet has more calories from lipids $(22 \%)$ and less carbohydrate (10\%) and protein (12\%) compared to the control diet. The rats were housed individually in metabolic cages in an environmentally controlled room (light from $6 \mathrm{AM}$ to $6 \mathrm{PM}, 23 \pm 1^{\circ} \mathrm{C}$ ) and had free access to food and water.

The body weight, water intake, and food intake of each rat were recorded daily. Glycaemia was measured every 3 days using test strips (AccuChek). Urine samples were also collected every 3 days for glucose and urea urinary determinations. The animals received their respective diets for a period of 12 days, and on the $13^{\text {th }}$ day, a single dose of STZ was administered intraperitoneally $(40 \mathrm{mg} /$ $\mathrm{kg}$ body weight) to animals fasted for $12 \mathrm{~h}$ in the HF-STZ group. The control animals received only vehicle (0.01 M citrate buffer, $\mathrm{pH} 4.5)$. After 3 days of induction with STZ (on the $16^{\text {th }}$ day of treatment), blood glucose was measured to confirm the establishment of diabetes. Animals were considered 
TABLE Ia

Calories and chemical composition (g/100 g) of Labina feed.

\begin{tabular}{lccc}
\hline Composition of comercial Labina feed & g/100g & Cal/100g & $\begin{array}{c}\text { \% of total caloric } \\
\text { value }\end{array}$ \\
\hline Carbohydrate & 52 & 208 & 61 \\
Lipid & 5 & 45 & 26 \\
Protein & 22 & 88 & 26 \\
Water & 10 & & \\
Ash & 11 & 341 Cal/100g or 1432 \\
Total energy & & $\mathrm{J} / 100 \mathrm{~g}$ \\
\hline
\end{tabular}

Sales 2011.

TABLE Ib

Ingredients and chemical composition (g/100 g) of high-fat diet.

\begin{tabular}{|c|c|c|c|}
\hline Ingredients of high-fat diet & $\mathrm{g} / 100 \mathrm{~g}$ & & \\
\hline Comercial Labina feed & 66.5 & & \\
\hline Lard & 13.5 & & \\
\hline Sucrose & 20 & & \\
\hline Composition of high-fat diet & $\mathrm{g} / \mathbf{1 0 0 g}$ & $\mathrm{Cal} / \mathbf{1 0 0 \mathrm { g }}$ & $\begin{array}{c}\% \text { of total caloric } \\
\text { value }\end{array}$ \\
\hline Carbohydrate & 54.5 & 218 & 51 \\
\hline Lipid & 16.8 & 151.2 & 35 \\
\hline Protein & 15.0 & 60 & 14 \\
\hline Total energy & & $\begin{array}{c}429 \mathrm{Cal} / 100 \mathrm{~g} \text { or } \\
1802 \mathrm{~J} / \mathrm{g}\end{array}$ & \\
\hline
\end{tabular}

diabetic if they had postprandial glycaemia values greater than or equal to $288 \mathrm{mg} / \mathrm{dL}$. The scheme of the experimental model is presented in Figure 1. The animals were maintained according to the Brazilian College of Animal Experimentation, and the study was approved by the Ethics Committee of the Federal University of Mato Grosso (protocol no. 23108.085196/2015-96).

\section{GLYCEMIC RESPONSE TO GLUCOSE ADMINISTRATION}

The evaluation of the glycemic response to the oral glucose administration (OGTT) was performed on diabetic and control animals that had been fasting for 15 hours. These animals received a glucose load of $2.5 \mathrm{~g} / \mathrm{kg}$ body weight on the $24^{\text {th }}$ day after the STZ administration $\left(37^{\text {th }}\right.$ day of the experimental period). The glucose load was administered through an orogastric gavage. Plasma glucose was measured before $(\mathrm{t}=0)$ and after the glucose administration (15, 30, 45, 60, 75 and 90 minutes).

\section{SAMPLE COLLECTION}

At the end of the experimental period ( $39^{\text {th }}$ day), the animals were sacrificed by decapitation between 7 and 10 AM. Blood samples were collected into tubes containing an anticoagulant to determine the glucose levels in the plasma. Serum was collected to determine the concentration of triglycerides, total cholesterol, HDL cholesterol, VLDL cholesterol, and LDL cholesterol. Groups of rats (Control group; $\mathrm{n}=6$; HF-STZ group; $\mathrm{n}=5$ ) were fasted for $12 \mathrm{~h}$ and samples of blood were 


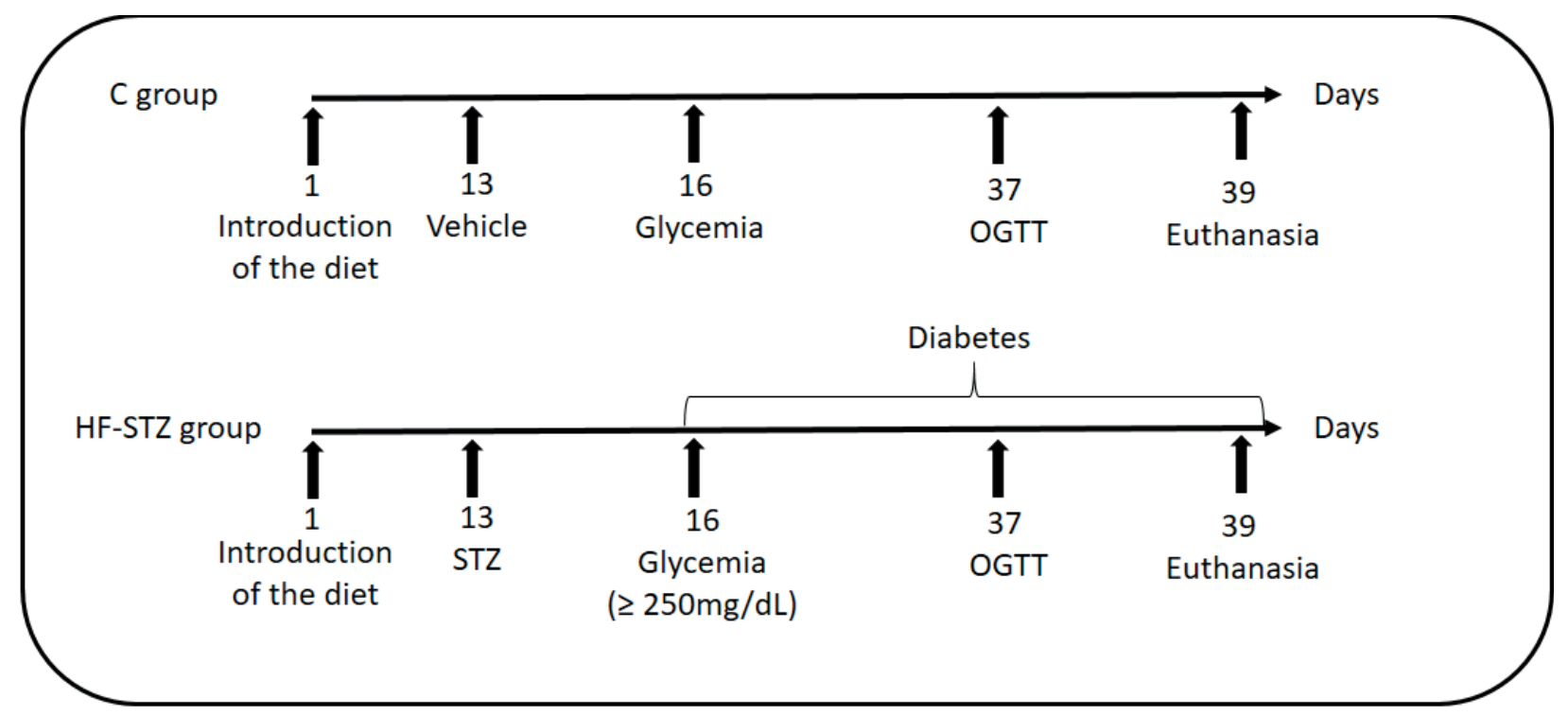

Figure 1 - Experimental design

Rats received an intraperitoneal (i.p.) injection of streptozotocin (STZ) or vehicle on the $13^{\text {th }}$ day of high-fat or control diets. After three days (on the $16^{\text {th }}$ day of treatment), the animals were subjected to glycemic tests. On the $37^{\text {th }}$ day, oral glucose tolerance tests were performed. On the $39^{\text {th }}$ day, the animals were sacrificed for analyses.

collected for determination of concentration of insulin, glucose and glucagon using commercial kits. The tissues were removed, weighed, and stored at $-80^{\circ} \mathrm{C}$ to measure the lipids and glycogen content. The carcasses were eviscerated, weighed and stored at $-20^{\circ} \mathrm{C}$ for chemical composition analysis. Biochemical analyses were performed by enzymatic colorimetric methods using commercial kits (Labtest and Bioclin). Insulin and glucagon in the blood were determined by ELISA assays using commercial kits (Sigma-Aldrich Inc., At. Louis, MO, USA). The homeostasis model assessment of insulin resistance (HOMA-IR) index was calculated for each rat as: HOMA-IR $=$ [fasting insulin $(\mu \mathrm{U} /$ $\mathrm{mL}) \mathrm{x}$ fasting glucose $(\mathrm{mmol} / \mathrm{L})] / 22.5$. This index is a predictor of insulin resistance (Bowe et al. 2014).

\section{LIPID AND GLYCOGEN DETERMINATION}

Lipids from the liver and retroperitoneal (RET), epidydimal (EPI), and perirenal (PERI) white adipose tissues were determined by gravimetric methods after chloroform-methanol $(2: 1)$ extraction according to Folch et al. (1957). A method from Carroll et al. (1956) was used to determine hepatic and muscle glycogen levels.

\section{CARCASS COMPOSITION AND ENERGY INTAKE}

Carcass water, fat, protein content, and ash were determined as described by Aparecida de França et al. (2009). Water content was measured as the difference between wet and dry weights, the latter obtained by oven-drying at $105^{\circ} \mathrm{C}$ to a constant weight. Fat content was obtained after extraction from the dry carcass with petroleum ether. Ash content was estimated following combustion at $550^{\circ} \mathrm{C}$ to a constant weight. Protein content was determined by subtracting the water, fat, and ash contents from the wet carcass weight.

Energy gain was calculated as the difference between the carcass energy at the end of the experiment and the carcass energy on the first day (baseline) (Ferreira et al. 2007, Aparecida de França et al. 2009). Carcass energy was calculated as previously described (Aparecida de França et al. 2009). 


\section{STATISTICAL ANALYSIS}

The results are expressed in terms of the mean \pm standard error (SE). The data were subjected to statistical analyses using Statistics for Windows (StatSoft, USA) or GraphPad Prim. Levene's test for homogeneity was initially used to determine whether the data complied with the assumptions required for parametric analysis. When necessary, the data were log-transformed to correct for variance in heterogeneity or non-normality (Sokal and Rohlf 1995). To evaluate food intake, body weight, water intake, and the urinary volume, glucose, and urea, repeated-measures ANOVA was used to analyze the effect of diet versus time, and a student's t-test was used to evaluate the difference between groups for independent samples. The differences were considered significant at $\mathrm{P} \leq 0.05$.

\section{RESULTS}

In the first 12 days of treatment before induction with STZ, the body weight gains were $64 \pm 12 \mathrm{~g}$ and $70 \pm 11 \mathrm{~g}$ in the HF-STZ and control groups, respectively. From the $16^{\text {th }}$ day until the end of treatment ( $39^{\text {th }}$ day), the weight gains were $6 \pm 2$ $\mathrm{g}$ in the HF-STZ group (diabetic) and $51 \pm 9 \mathrm{~g}$ in the control group (Table II). Food intake and body weight during the experimental period were lower in the HF-STZ group than in the control group (Figures $2 \mathrm{a}$ and $2 \mathrm{~b}$ ).
The HF-STZ group showed a reduction of $14 \%$ in absolute food intake (daily and total) in the 12 days before the induction with STZ compared to the control group (Table III). After induction with STZ (16 ${ }^{\text {th }}$ day), the daily and total absolute intake remained lower by approximately $14 \%$ in the HFSTZ group (diabetics) compared to control group. No difference was observed in daily and total absolute energy intake in first 12 days and after the STZ administration (Table III) in both groups. However, total relative energy intake increased $38 \%$ in the HF-STZ group compared to the control group. There were no significant differences in the other parameters evaluated (Table III).

Compared with the control animals, HF-STZ animals had reductions of $28 \%$ in carcass weight, $26 \%$ in water, $22 \%$ in protein content, and $66 \%$ in carcass fat. Although total relative energy intake were higher in HF-STZ animals, their carcass energy (39\%) and energy gain (75\%) were lower (Table IV). There were reductions of $38 \%$ in epidydimal adipose tissue (EPI), $18 \%$ in the soleus, and $20 \%$ in the extensor digitorum longus (EDL) muscles in the HF-STZ group (Table V). There was no change in weight of the other tissues evaluated. Glycogen content was reduced by $71 \%$ in the liver, $75 \%$ in the soleus muscle, and $80 \%$ in the EDL muscle in the HF-STZ group compared to the control group (Table V). There were no significant changes in lipid content in the tissues between groups.

\section{TABLE II}

Body mass before streptozotocin (STZ) administration $\left(12^{\text {th }}\right.$ day), body mass after STZ administration (diabetics), and final body mass $\left(39^{\text {th }}\right.$ day) of male rats subjected to control diet (C) or high-fat diet/ streptozotocin (HF-STZ).

\begin{tabular}{lcc}
\hline Variables & $\begin{array}{c}\text { C group } \\
(\mathbf{n}=\mathbf{6})\end{array}$ & $\begin{array}{c}\text { HF-STZ group } \\
(\mathbf{n = 1 0})\end{array}$ \\
\hline Body mass before STZ $\left(12^{\text {th }}\right.$ day $)(\mathrm{g})$ & $320.2 \pm 15.2$ & $305.7 \pm 9.1$ \\
Body mass after STZ (diabetics) $\left(16^{\text {th }}\right)(\mathrm{g})$ & $338.4 \pm 16.8$ & $293.6 \pm 10.6^{*}$ \\
Final body mass $\left(39^{\text {th }}\right.$ day $)(\mathrm{g})$ & $389.6 \pm 19.1$ & $299.2 \pm 10.2^{*}$ \\
\hline
\end{tabular}

Data are expressed as mean \pm standard error of the number of animals (n) indicated in parentheses. $* \mathrm{P}<0.05$ versus controls (Student's t test). 
(a)

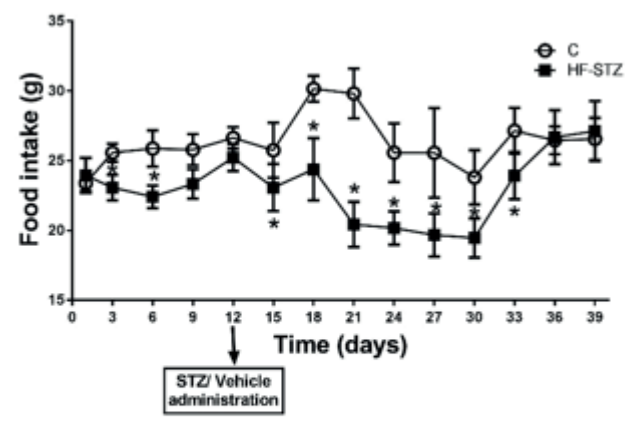

(c)

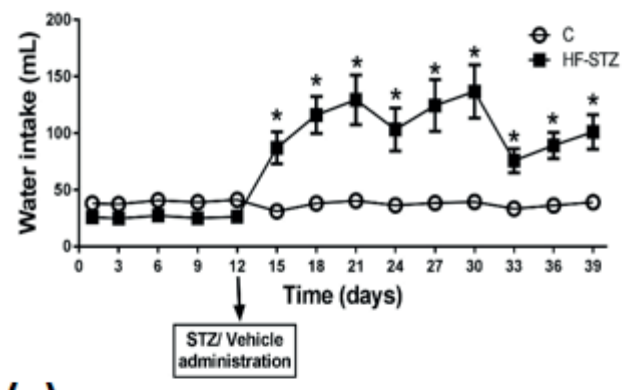

(e)

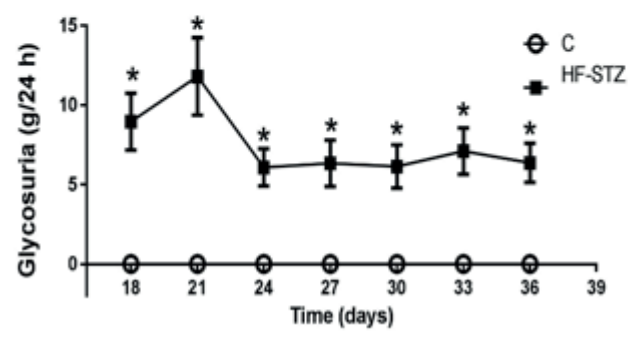

(b)

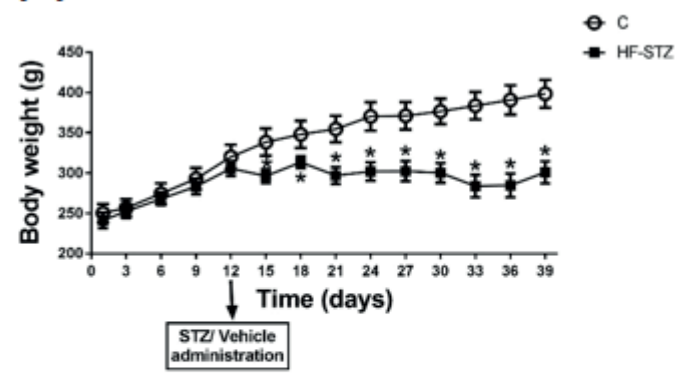

(d)

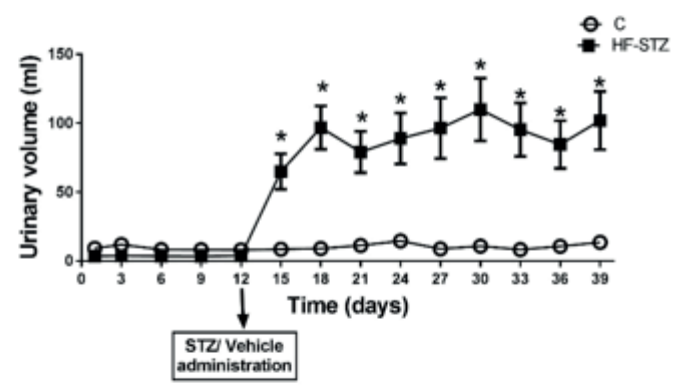

(f)

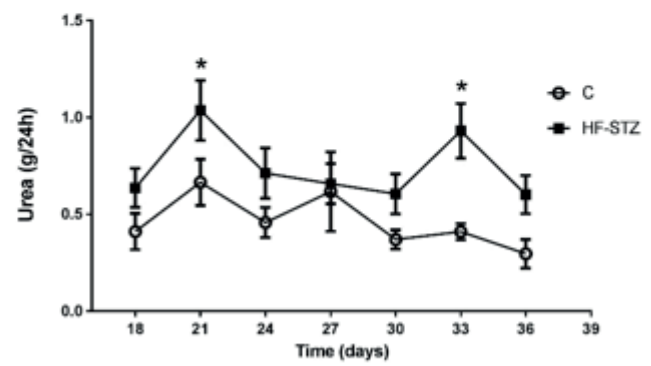

Figure 2 - Food intake (a), body weight (b), water intake (c), urinary volume (d), glycosuria (e), and urinary urea (f) of the male rats subjected to control diet (C) and high-fat diet/ streptozotocin (HF-STZ) for 39 days. Repeated-measures ANOVA for HF-STZ group (food intake: treatment $\mathrm{P}=0.0282$, individual $\mathrm{P}=0.0004$; body weight: treatment $\mathrm{P}=0.0085$, individual $\mathrm{P}<0.0001$; water intake and urinary volume: treatment and individual $\mathrm{P}<0.0001$; glycosuria: treatment $\mathrm{P}=0.0018$, individual $\mathrm{P}<0.0001$; urea: treatment $\mathrm{P}=0.0283$, individual $\mathrm{P}<0.0001$ ). Results are expressed as mean \pm standard error across six control animals and ten HF-STZ animals in each analysis. *Statistical difference versus $\mathrm{C}$ group; student's t-test $(\mathrm{P}<0.05)$.

Water intake (Figure 2c), urine volume (Figure 2d), glucose (Figure 2e), and urea in the urine (Figure 2f) were higher as the treatment progressed in the HF-STZ group than in the control group. Figure 3 shows the glycemic parameters assessed in the blood. On the $12^{\text {th }}$ day of administration of the HF diet, blood glucose in the HF-STZ group $(118 \pm 1 \mathrm{mg} / \mathrm{dL})$ was higher than in the control group $(107 \pm 2 \mathrm{mg} / \mathrm{dL})$. After induction with STZ, there was a $234 \%$ increase in glucose levels in the HF-STZ group (HF-STZ $=404 \pm 46 \mathrm{mg} / \mathrm{dL}$; control $=121 \pm 2 \mathrm{mg} / \mathrm{dL})$. These values remained increased until the end of the experimental period ( $39^{\text {th }}$ day) (Figure 3). The mean postprandial glucose levels were $327 \pm 27 \mathrm{mg} / \mathrm{dL}$ in the HF-STZ group and 111 $\pm 1 \mathrm{mg} / \mathrm{dL}$ in the control group. The HF-STZ group 
TABLE III

Total and dairy absolute food intake and total and dairy energy intake of male rats subjected to control diet (C) or highfat diet/ streptozotocin (HF-STZ) before and after streptozotocin (STZ) administration.

\begin{tabular}{|c|c|c|}
\hline \multicolumn{3}{|c|}{ Before STZ administration $\left(1^{\text {st }}-12^{\text {th }}\right.$ day) } \\
\hline Variable & $\begin{array}{c}\text { C group } \\
(n=6)\end{array}$ & $\begin{array}{c}\text { HF-STZ group } \\
(n=10)\end{array}$ \\
\hline \multicolumn{3}{|l|}{ Dairy } \\
\hline Absolute food intake (g) & $27.0 \pm 1.6$ & $23.2 \pm 0.7^{*}$ \\
\hline Energy intake (kJ) & $349.5 \pm 21.3$ & $396.8 \pm 10.2$ \\
\hline \multicolumn{3}{|l|}{ Total } \\
\hline Absolute food intake (g) & $324.1 \pm 19.7$ & $279.1 \pm 7.1^{*}$ \\
\hline Energy intake $(\mathrm{kJ})$ & $4194.1 \pm 255.9$ & $4761.6 \pm 122.5$ \\
\hline \multicolumn{3}{|c|}{ After STZ administration $\left(16^{\text {th }}-39^{\text {th }}\right.$ day $)$} \\
\hline Variable & $\begin{array}{c}\text { C group } \\
(n=6)\end{array}$ & $\begin{array}{c}\text { HF-STZ group } \\
(n=10)\end{array}$ \\
\hline \multicolumn{3}{|l|}{ Dairy } \\
\hline Absolute food intake (g) & $26.3 \pm 1.1$ & $22.7 \pm 1.0 *$ \\
\hline Relative food intake (g/100g) & $7.1 \pm 0.2$ & $7.8 \pm 0.5$ \\
\hline Energy intake $(\mathrm{kJ})$ & $340.9 \pm 14.6$ & $388.8 \pm 18.1$ \\
\hline \multicolumn{3}{|l|}{ Total } \\
\hline Absolute food intake (g) & $605.9 \pm 25.9$ & $524.2 \pm 24.3^{*}$ \\
\hline Relative food intake (g/100g) & $163.0 \pm 4.3$ & $179.0 \pm 11.6$ \\
\hline Energy intake (kJ) & $7840.7 \pm 335.7$ & $8942.7 \pm 415.2$ \\
\hline Relative energy intake $(\mathrm{kJ} / 100 \mathrm{~g})$ & $2335.5 \pm 61.7$ & $3221.3 \pm 208.3 *$ \\
\hline
\end{tabular}

Data are expressed as mean \pm standard error of the number of animals (n) indicated in parentheses. $* \mathrm{P}<0.05$ versus controls (Student's t test).

also showed an increase of $301 \%$ in fasting glucose levels (Figure 3).

In the oral glucose tolerance test, the area under the curve was $282 \%$ higher in the HF-STZ group than in the control group, which confirms the reduced glucose tolerance in animals that received the HF diet associated with STZ (Figure 4). The HFSTZ group also showed increases of approximately $330 \%$ in postprandial triglycerides and VLDL cholesterol levels at the end of the experiment. Fasting triglyceride and VLDL cholesterol levels were also approximately $90 \%$ higher than in the control group under the same conditions. No significant differences were observed in the other parameters evaluated (Table VI).

There was no difference in the insulin levels between groups. However, the HOMA-IR index was 4 times higher in the HF-STZ group. Glucagon levels were $23 \%$ lower in the HF-STZ group. No difference was observed in the ratio of insulin to glucagon (Table VII).

\section{DISCUSSION}

Our goal was to establish an experimental diabetes model in rats with characteristics of human DM2 using rats fed an HF diet and dosed with STZ i.p. Previous studies used different types of diet with 


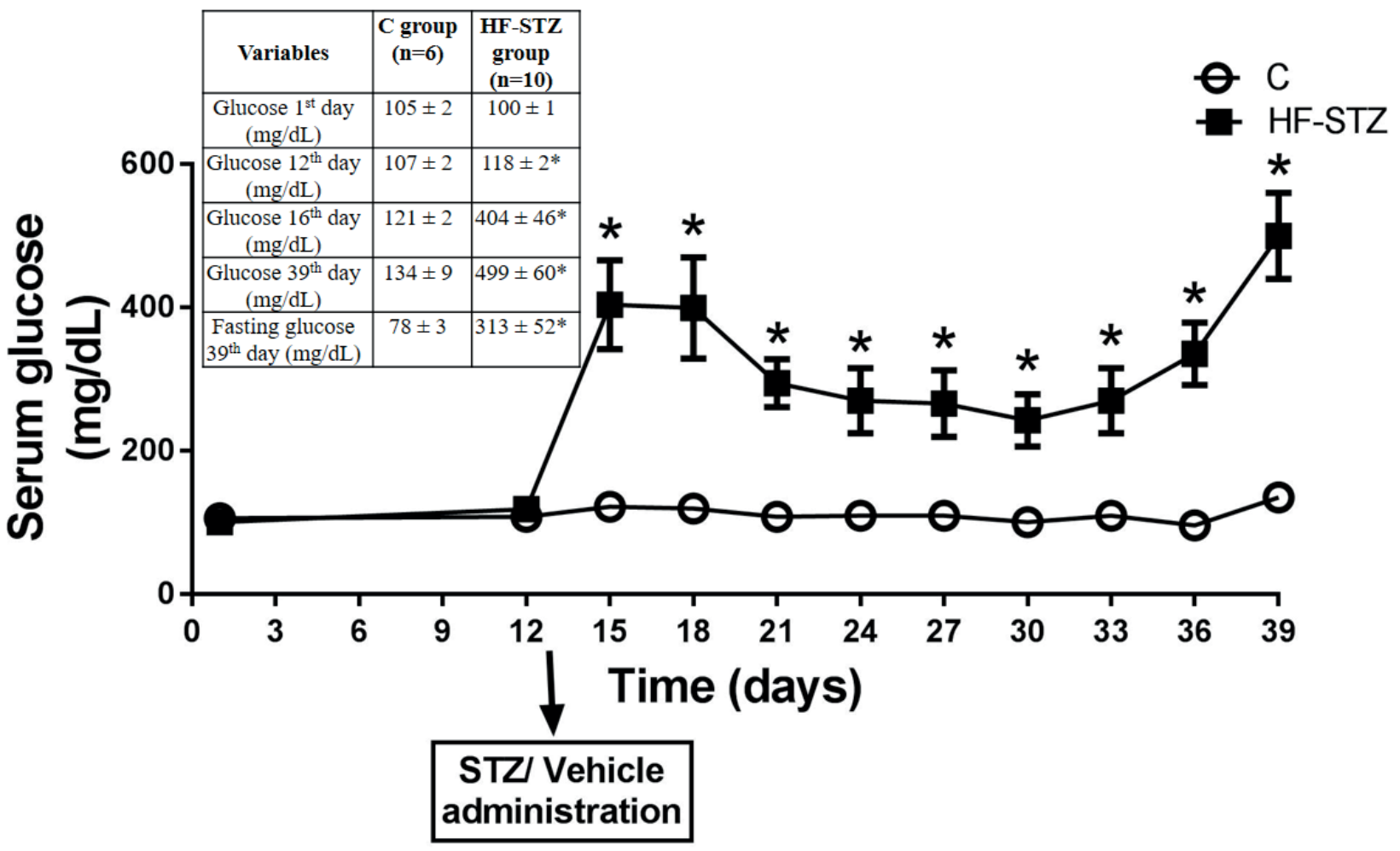

Figure 3 - Serum glucose (mg/dL) of fed male rats subjected to control diet (C) and high-fat diet/ streptozotocin (HF-STZ) for 39 days. Values in the table and figure are expressed as mean \pm standard error across six control animals and ten HF-STZ animals in each analysis. Repeated-measures ANOVA for HF-STZ group (treatment $\mathrm{P}=0.0045$, individual $\mathrm{P}<0.0001$ ), ${ }^{*}$ statistical difference versus $\mathrm{C}$ group, student's t-test $(\mathrm{P}<0.05)$.

TABLE IV

The carcass composition of male rats subjected to control diet (C) or high-fat diet/ streptozotocin (HF-STZ).

\begin{tabular}{lcc}
\hline Variable & $\begin{array}{c}\text { C group } \\
(\mathbf{n = 4})\end{array}$ & $\begin{array}{c}\text { HF-STZ group } \\
(\mathbf{n}=\mathbf{5})\end{array}$ \\
\hline Carcass weight $(\mathrm{g})$ & $296.5 \pm 14.6$ & $213.3 \pm 6.3^{* *}$ \\
Water $(\mathrm{g})$ & $190.6 \pm 9.5$ & $141.7 \pm 3.5^{* *}$ \\
Fat $(\mathrm{g})$ & $25.1 \pm 5.6$ & $8.4 \pm 1.9^{* *}$ \\
Protein $(\mathrm{g})$ & $71.0 \pm 2.6$ & $55.0 \pm 1.9^{* *}$ \\
Ash $(\mathrm{g})$ & $9.8 \pm 0.9$ & $8.2 \pm 0.4$ \\
Baseline carcass $(\mathrm{Kj})$ & $1364.5 \pm 37.0$ & $1364.5 \pm 37.0$ \\
Carcass energy $(\mathrm{Kj})$ & $2685.5 \pm 227.1$ & $1640.7 \pm 98.2 * *$ \\
Energy gain $(\mathrm{Kj})$ & $1321.0 \pm 227.1$ & $333.05 \pm 98.1 * *$
\end{tabular}

Data are expressed as mean \pm standard error of the number of animals $(\mathrm{n})$ indicated in parentheses. $* *$ Student's $\mathrm{t}$ test $(\mathrm{P}<0.01)$. 


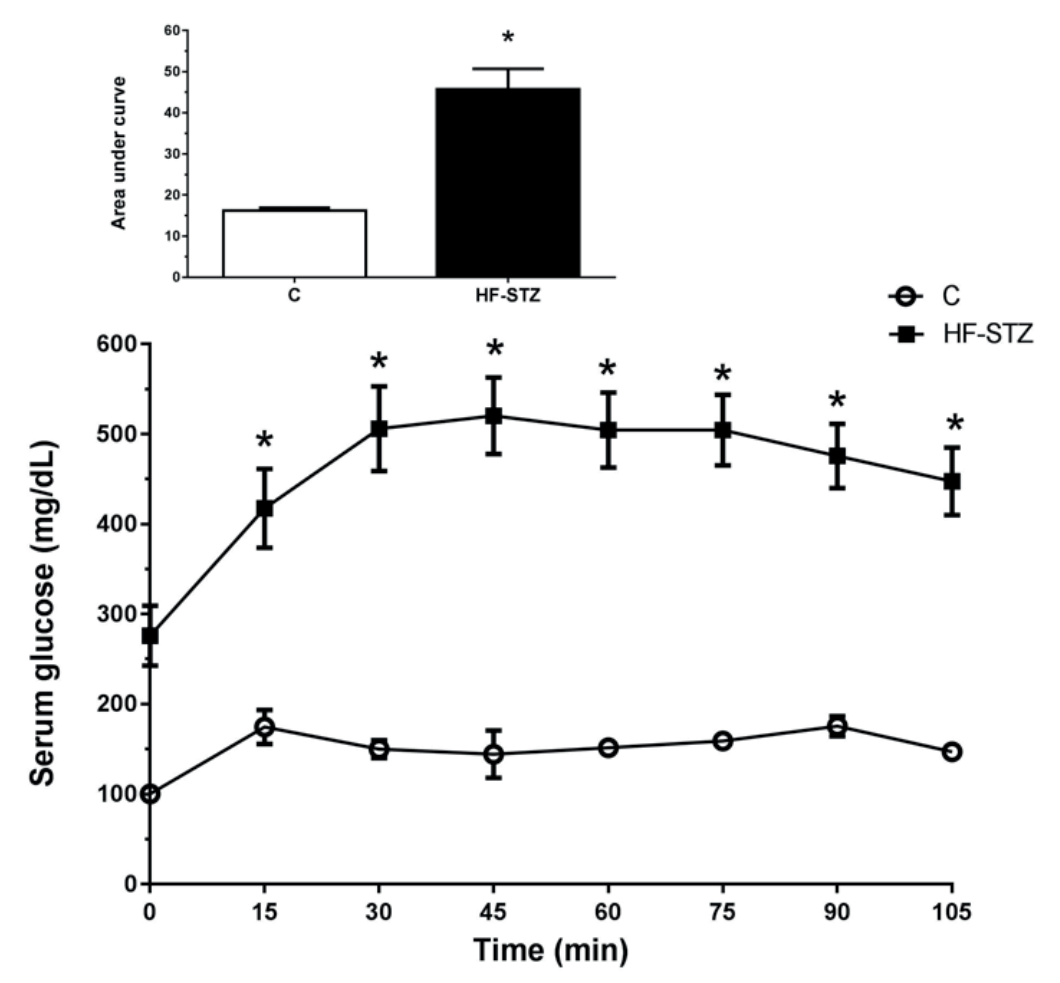

Figure 4 - Serum glucose $(\mathrm{mg} / \mathrm{dL})$ and area under curve of the oral glucose tolerance test (OGTT) of male rats subjected to control diet (C) and high-fat diet/ streptozotocin (HF-STZ) for 39 days. Results are expressed as mean \pm standard error across six control animals and ten HF-STZ animals in each analysis. * Statistical difference versus $\mathrm{C}$ group. Student's t-test $(\mathrm{P}<0.05)$.

different doses of STZ to induce DM2 (Srinivasan et al. 2005, Correia-Santos et al. 2012, Zhang et al. 2015). There is a consensus that the use of HF diets is efficient for the induction of DM2, but the amount of lipids used in the diet has not been clearly established: 60\% (Correia-Santos et al. 2012); 58\% (Srinivasan et al. 2005); 45\% (Atanasovska et al. 2014); 10\% (Zhang et al. 2015). The protocol used in this work was adapted from Zhang et al. (2015), who prepared the HF diet using commercial standard rodent diet with the addition of lard. The use of the HF diet using commercial feed is based on the effects that this type of diet can have in rodents and not of each item of its composition.

Different doses of STZ have been associated with models of DM based on STZ and HF diet. STZ doses greater than $45 \mathrm{mg} / \mathrm{kg}$ of body weight (i.p.) associated with HF diets induced hyperglycemia, but these animals did not respond to conventional treatment with metformin (oral hypoglycemic agent), probably due to the occurrence of DM1 (Arulmozhi et al. 2004, Srinivasan et al. 2005). On the other hand, doses below $25 \mathrm{mg} / \mathrm{kg}$ (i.p.) did not produce hyperglycemia in animals receiving HF diets for 2 weeks (Srinivasan et al. 2005).

Srinivasan et al. (2005) presented positive results with their DM2 model using a dose of 35 $\mathrm{mg} / \mathrm{kg}$ (i.p.) in rats fed a HF diet. Our study was conducted with a dose of $40 \mathrm{mg} / \mathrm{kg}$ (i.p.) of STZ given to the animals in the HF group since we used older animals (10 weeks vs. 7 weeks (Srinivasan et al. 2005)). Our HF diet had a lower percentage of lipids (35\% of total calories) compared to that used by Srinivasan et al. (2005) (58\% of total calories).

An important factor in the determination of animal models using HF-STZ diets is the age of the 
TABLE V

Tissue weight, lipid, and glycogen contents of male rats subjected to control diet (C) or high-fat diet/ streptozotocin (HF-STZ).

\begin{tabular}{|c|c|c|c|c|c|c|}
\hline \multirow[b]{2}{*}{ Variables } & \multicolumn{2}{|c|}{ Tissue weight (g) } & \multicolumn{2}{|c|}{ Lipid (mg/g of tissue) } & \multicolumn{2}{|c|}{ Glycogen ( $\mathrm{mg} / \mathrm{g}$ of tissue) } \\
\hline & $\begin{array}{c}\text { C group } \\
(n=6)\end{array}$ & $\begin{array}{c}\text { HF-STZ } \\
\text { group } \\
(\mathrm{n}=10)\end{array}$ & $\begin{array}{c}\text { C group } \\
(\mathrm{n}=6)\end{array}$ & $\begin{array}{c}\text { HF-STZ } \\
\text { group } \\
(\mathrm{n}=10)\end{array}$ & $\begin{array}{c}\text { C group } \\
(n=6)\end{array}$ & $\begin{array}{c}\text { HF-STZ } \\
\text { group } \\
(\mathrm{n}=10)\end{array}$ \\
\hline Liver & $13.9 \pm 1.2$ & $11.6 \pm 0.6$ & $34.5 \pm 1.3$ & $41.5 \pm 2.1$ & $30.2 \pm 2.7$ & $8.5 \pm 3.3 *$ \\
\hline Retroperitoneal & $5.6 \pm 0.9$ & $3.3 \pm 0.9$ & $613.1 \pm 64.4$ & $607.1 \pm 18.4$ & - & - \\
\hline Epididymal & $6.2 \pm 0.7$ & $3.9 \pm 0.6^{*}$ & $618.4 \pm 14.1$ & $589.4 \pm 9.8$ & - & - \\
\hline Perirenal & $1.3 \pm 0.3$ & $0.9 \pm 0.2$ & $665.6 \pm 16.7$ & $613.3 \pm 16.5$ & - & - \\
\hline Soleus & $0.40 \pm 0.01$ & $0.33 \pm 0.01 *$ & - & - & $18.6 \pm 3.8$ & $4.6 \pm 0.6 *$ \\
\hline Extensor digitorum longus & $0.35 \pm 0.01$ & $0.28 \pm 0.01^{*}$ & - & - & $11.8 \pm 1.1$ & $2.3 \pm 0.6^{*}$ \\
\hline Kidney & $2.85 \pm 0.12$ & $2.80 \pm 0.10$ & - & - & - & - \\
\hline
\end{tabular}

Data are expressed as mean \pm standard error of the number of animals (n) indicated in parentheses. ${ }^{*} \mathrm{P}<0.05$ versus controls (Student's t test).

animal. Young rats have different behavior of adult rats. According to Bluestone et al. (2010), young rats receiving STZ and HF diets exhibited a great loss of $\beta$-cell function that mimicked DM1 in obese children, but without the autoimmune component present in DM1. On the other hand, young rats that receive HF-STZ diets and present lower depletion of $\beta$-cell mass mimic obese children with DM2. Pani et al. (2008) states that the pathogenesis of DM2 in young and older individuals has different evolutions. Young individuals with DM2 have a tendency to be deficient in insulin, since older individuals tend to be more insulin resistant (Pani et al. 2008). Another important point is that young rats have more ability to increase $\beta$-cell mass than older (aged over 1 year), which is also the case in young humans (Kushner 2013).

$\mathrm{STZ}$ is a drug that promotes damage to pancreatic $\beta$ cells and compromises insulin production. Thus, in order to reach our goal, the animals of the HF-STZ group should present a loss of body weight due to intense proteolysis and lipolysis, as well as increased food intake. Due to increased blood glucose levels, osmotic diuresis should occur with a loss of glucose and excess urine volume, resulting in increased water intake. Another characteristic of diabetes is an increase in urea production due to proteolysis and increased neoglycogenesis associated with a reduction of glycogenesis and increased glycogenolysis, as well as a reduction in hepatic and muscular glycogen content. DM2 is also usually associated with a change in the lipid profile with increases in triglycerides, total cholesterol, and LDL cholesterol, as well as a reduction in serum HDL cholesterol levels.

The present results are similar to those reported by Hariri et al. (Hariri et al. 2010). Both studies showed a reduction in dietary intake after offering HF diets in the adaptation period to the diet. High fat diets stimulate the release of hormones that promote satiety (cholecystokinine, peptide 
TABLE VI

Biochemical analyses of male rats subjected to control diet (C) or high-fat diet/ streptozotocin (HF-STZ).

\begin{tabular}{lcc}
\hline Variables & $\begin{array}{c}\text { C group } \\
(\mathbf{n}=\mathbf{6})\end{array}$ & $\begin{array}{c}\text { HF-STZ group } \\
\text { (n=10) }\end{array}$ \\
\hline Fed state & & $346 \pm 81^{*}$ \\
Triglyceride (mg/dL) & $82 \pm 14$ & $181 \pm 18$ \\
Total cholesterol (mg/dL) & $136 \pm 8$ & $65 \pm 6$ \\
HDL-cholesterol (mg/dL) & $85 \pm 8$ & $46 \pm 5$ \\
LDL-cholesterol (mg/dL) & $34 \pm 7$ & $69 \pm 16^{*}$ \\
VLDL-cholesterol (mg/dL) & $16 \pm 2$ & HF-STZ group \\
\hline Fasting state & $\mathbf{C ~ g r o u p ~}$ & (n=5) \\
\hline Triglyceride (mg/dL) & $81 \pm 13)$ & $158 \pm 38^{*}$ \\
Total cholesterol (mg/dL) & $118 \pm 6$ & $122 \pm 10$ \\
HDL-cholesterol (mg/dL) & $56 \pm 4$ & $53 \pm 5$ \\
LDL-cholesterol (mg/dL) & $46 \pm 5$ & $30 \pm 11$ \\
VLDL-cholesterol (mg/dL) & $16 \pm 3$ & $31 \pm 8^{*}$ \\
\hline
\end{tabular}

Data are expressed as mean \pm standard error of the number of animals (n) indicated in parentheses. $* \mathrm{P}<0.05$ versus controls (Student's t test).

YY, and glucagon-like peptide-1) (Ohlsson et al. 2014), which may have led to a reduction in food intake. The HF-STZ rats did not present significant differences in body weight after 12 days of diet, but they presented significantly lower body weight after STZ administration ( $16^{\text {th }}$ day) and continued with lower weight gain until the end of treatment $\left(39^{\text {th }}\right.$ day) when compared to the control group. Other studies also showed a reduction in the body weight of animals fed a HF diet with different STZ doses (Srinivasan et al. 2005, Correia-Santos et al. 2012, Jinshan et al. 2015). The weight loss of HFSTZ animals occurred with lower food intake, but the relative energy intake was higher during the period evaluated.

HF-STZ animals show reductions in carcass components (water, fat, and protein contents) and energy gain, even with higher total relative energy intake. These animals had reduced lipid carcass content without alteration in the retroperitoneal, epidydimal and perirenal lipid contents. On the other hand, HF-STZ animals presented a loss of muscle mass evidenced by reductions in the soleus and EDL muscles and carcass protein content. Studies show that obesity and lipodystrophy lead to insulin resistance in muscles (Muoio and Newgard 2008). In addition, the downregulation of adipose GLUT4 observed in mice can cause insulin resistance in muscles and the liver (Abel et al. 2001).

Adipose tissue can modulate glucose metabolism by regulating fatty acid levels in circulation and by secreting adipokines (Muoio and Newgard 2008). Increased free fatty acid (FFA) circulation may impair insulin sensitivity in muscle by inhibiting IRS/PI3 kinase, which would result in the reduction of GLUT4 translocation to the plasma membrane. In addition, FFA can enhance serine phosphorylation of the IRS protein and thus impair insulin signal transduction (White 2002). The reduction in hepatic and muscular glycogen results in reduced action of insulin in the muscle and liver. In addition, the lack of change in the 
TABLE VII

Hormonal analyses of male rats subjected to control diet (C) or high-fat diet/ streptozotocin (HF-STZ).

\begin{tabular}{lcc}
\hline Variables & C group & HF-STZ group \\
$(\mathbf{n = 6})$ & $\mathbf{5})$ \\
\hline Insulin $(\mu \mathrm{UI} / \mathrm{mL})$ & $8.3 \pm 0.5$ & $8.4 \pm 0.9$ \\
HOMA-IR index & $1.6 \pm 0.1$ & $6.9 \pm 1.6^{* *}$ \\
Glucagon $(\mathrm{pg} / \mathrm{mL})$ & $72.2 \pm 3.0$ & $55.6 \pm 5.5^{*}$ \\
Insulin/glucagon ratio $(\mu \mathrm{UI} / \mathrm{pg})$ & $0.12 \pm 0.01$ & $0.15 \pm 0.01$ \\
\hline
\end{tabular}

Data are expressed as mean \pm standard error of the number of animals (n) indicated in parentheses. $* \mathrm{P}<0.05 ; * * \mathrm{P}<0.01$ versus controls (Student's t test).

basal insulin levels of diabetic animals and the hyperglycemia observed throughout the experiment indicate the reduction of insulin action in peripheral tissues. These metabolic alterations associated with the results obtained by the OGTT and the higher HOMA-IR index indicate an insulin-resistant status.

HF-STZ animals had unchanged basal insulin levels (Table VII). The values of serum insulin presented were obtained on the $39^{\text {th }}$ day (last day) when they were 15 weeks old (almost 4 months old). We believe that when STZ is administered to rats ( $13^{\text {th }}$ day), $\beta$ cells are "partially" destroyed; subsequently, there is an increase in the mass by division of surviving cells increasing the production of insulin. The data on serum glucose is represented in Figure 3, corroborating this hypothesis. We can observe that rats of HF-STZ group showed an increase in the glucose concentration $\left(16^{\text {th }}\right.$ and $18^{\text {th }}$ days), but from $21^{\text {st }}$ until $36^{\text {th }}$ day the level of serum glucose decreased suggesting an increase in the insulin secretion. The increase in glucose on the $39^{\text {th }}$ day (with the same insulin level as control animals) may mean that the insulin resistance installed by HF diet is not compensated by additional insulin secretion. Rankin and Kushner (2009), in their study about $\beta$-cell regeneration ability observed in partially pancreatectomized mice, showed that $\beta$-cell regeneration capacity changes as a function of age. The authors demonstrated $\beta$-cell regeneration was more robust in 1.5-month-old and 8-month- old mice and much lower in 12-month-old mice. In older mice (older than 12 months), regeneration capacity was barely detectable in 14-month-old mice and absent in 18-month-old mice. Thus, these facts can justify why the animals of HF-STZ group show unchanged insulin levels at the end of the experiment when compared with control animals (15 weeks old/ 4 months old, approximately).

A diabetic state or lack of insulin action is characterized by intense proteolysis and lipolysis, which may explain the reduction in the weight of the soleus and EDL muscles, as well as in the weight of epididymal adipose tissue. Changes in the activity of different proteolytic pathways in skeletal muscle are observed in STZ-induced diabetic rats (Pepato et al. 1996). The intense proteolysis observed in the HF-STZ group may explain the increase in urea secretion (Figure 2f). Thus, muscle catabolism associated with reduced lipid reserves may be associated with the lower body weight observed in the HF-STZ group.

The glycaemia of the HF-STZ group was higher than in the control group (Figure 3). On the $12^{\text {th }}$ day of HF diet administration prior to STZ induction, the glycaemia of the these animals was slightly higher than in the control group. These values increased after induction with STZ remained elevated until the end of the experimental period (both postprandial glycaemia and fasting glycaemia). The transition from pre-diabetes to diabetes (hyperglycemia) is associated with a 
decline in the secretory capacity of pancreatic $\beta$ cells to compensate for existing insulin resistance, leading to a stage of hyperglycemia.

Figure $2 \mathrm{e}$ shows that in the urine, there is almost no glucose throughout the period evaluated in the control group, while in the HF-STZ group, it was around $10 \mathrm{~g}$ in the first days and remained around $7 \mathrm{~g}$ of glucose in a $24 \mathrm{~h}$ period until the end of the evaluation. Increased urinary volume (Figure 2d) was accompanied by glycosuria, which is characteristic of osmotic diuresis. As a consequence, these animals also showed an increase in water intake (Figure 2c). All reported changes are characteristic of diabetic animals.

The animals in the HF-STZ group presented hypertriglyceridemia when compared to the control group. Although not statistically different, the animals also presented high values of total cholesterol and reduced HDL cholesterol. One of the possible causes of these differences not being statistically significant is the short exposure to the HF diet, since other studies with prolonged exposures to HF diets show alterations in the lipid profile. Alteration of the lipid profile is commonly associated with DM2. Other models using HF diets also showed elevated serum triglycerides and total circulating free fatty acids (MJ Reed et al. 2000, Srinivasan et al. 2005, Jinshan et al. 2015), in addition to the reduction in HDL cholesterol (Jinshan et al. 2015).

The synthesis and maintenance of glycogen stores are some of the very characteristic actions of insulin. The reduction in glycogen content shows that the action of insulin may be compromised, since the level of serum insulin was not affected in these rats. The difficulty in maintaining normal glycemic levels in the HF-STZ group observed in OGTT confirms the impairment of the response to glucose overload. This is one of the first altered parameters in the evolution of DM2.

Thus, we conclude that the association of HF diet with a dose of STZ administered intraperitoneally in adult animals was effective in generating a DM2 in rats, with metabolic characteristics similar to those of human DM2.

\section{ACKNOWLEDGMENTS}

We would like to thank Celso Roberto Afonso and Cristina Helena Alves for technical assistance. This work was supported by a grant from the Fundação de Amparo à Pesquisa do Estado de Mato Grosso (FAPEMAT) and Coordenação de Aperfeiçoamento de Pessoal de Nível Superior (CAPES). We thank Labtest by "Projeto Universidade". There are neither financial nor non-financial competing interests.

\section{AUTHOR CONTRIBUTIONS}

Researches DAM, WTK and FSC carried out animal experimental and biochemical determinations. TSQ carried out lipid and glygogen analyses. EWAN analyzed carcass composition. MPS and NHK, read the manuscript and contributed to the discussion. SAF designed the experiment, helped analyze the data, wrote the manuscript, and supervised the project.

\section{REFERENCES}

ABEL ED, PERONI O, KIM JK, KIM YB, BOSS O, HADRO E, MINNEMANN T, SHULMAN GI AND KAHN BB. 2001. Adipose-selective targeting of the GLUT4 gene impairs insulin action in muscle and liver. Nature 409: 729-733.

APARECIDA DE FRANÇA S, DOS SANTOS MP, GAROFALO MA, NAVEGANTES LC, KETTELHUT IDO C, LOPES CF AND KAWASHITA NH. 2009. Low protein diet changes the energetic balance and sympathetic activity in brown adipose tissue of growing rats. Nutrition. 25: 1186-1192.

ARULMOZHI DK, VEERANJANEYULU A AND BODHANKAR SL. 2004. Neonatal streptozotocininduced rat model of Type 2 diabetes mellitus: A glance. Indian J Pharmacol 36(4): 217-221.

ATANASOVSKA E, TASIC V, SLANINKA-MICESKA M, ALABAKOVSKA S, ZAFIROV D, KOSTOVA E, PAVLOVSKA K, FILIPCE V AND LABACEVSKI N. 2014. Six week follow-up of metabolic effects induced by 
a high-fat diet and streptozotocin in a rodent model of type 2 diabetes mellitus. Contributions. Sec Med Sci, XXXV. 35: $169-179$.

BLUESTONE JA, HEROLD K AND EISENBARTH G. 2010. Genetics, pathogenesis and clinical interventions in type 1 diabetes. Nature 464: 1293-1300.

BOWE JE, FRANKLIN ZJ, HAUGE-EVANS AC, KING AJ, PERSAUD SJ AND JONES PM. 2014. Metabolic phenotyping guidelines: Assessing glucose homeostasis in rodent models. J Endocrinol 222(3): 13-25.

CARROLL NV, LONGLAY RW AND ROE JH. 1956. The determination of glycogen in liver and muscle by use of anthrone reagents. J Biol Chem 220: 583.

CORREIA-SANTOS AM, SUZUKI A, ANJOS JS, RÊGO TS, ALMEIDA KCL AND BOAVENTURA GT. 2012. Induction of Type 2 Diabetes by low dose of streptozotocin and high-fat diet-fed in wistar rats. Medicina (Ribeirão Preto) 45(4): 436-444.

DEFRONZO RA AND ABDUL-GHANI M. 2011. Type 2 Diabetes can be prevented with early pharmacological intervention. Diabetes Care 34: 202-209.

FERREIRA CL, MACEDO GM, LATORRACA MQ, ARANTES VC, VELOSO RV, CARNEIRO EM, BOSCHERO AC, NASCIMENTO CM AND GAÍVA MH. 2007. Serum leptin and insulin levels in lactating protein-restricted rats: implications for energy balance. Brit J Nut 97: 27-34.

FOLCH J, LEES M AND SLOANE STANLEY GH. 1957. A simple method for the isolation and purification of total lipides from animal tissues. J Biol Chem 226: 497-509.

HARIRI N, GOUGEON R AND THIBAULT L. 2010. A highly saturated fat-rich diet is more obesogenic than diets with lower saturated fat content. Nutr Res 30: 632-643.

JINSHAN J, ZHANG C, LUO X, WANG L, ZHANG R, WANG Z, FAN D, YANG H AND DENG J. 2015. Effect of stay-green wheat, a novel variety of wheat in China, on glucose ando lipid metabolism in high-fat diet induced type 2 diabetic rats. Nutrients 7: 5143-5155.

KAWAHITO S, KITAHATA H AND OSHITA S. 2009. Problems associated with glucose toxicity: role of hyperglycemia-induced oxidative stress. World J Gastroenterol 15: 4137-4142.

KUSHNER JA. 2013. The role of aging upon beta cell turnover. J Clin Invest 123: 990-995.

MAITRA A AND ABBAS AK. 2005. Endocrine system. In: Kumar V, Fausto N and Abbas AK (Eds), Robbins and Cotran Pathologic basis of disease (7th ed). Philadelphia, Saunders, $1156 \mathrm{p}$.

MJ REED K, MESZAROS LJ, ENTES MD, CLAYPOOL JG, PINKETT TM, GADBOIS AND REAVEN GM. 2000. A new rat model of type 2 diabetes: the fat-fed, streptozotocin-treated rat. Metabolism 49(11): 1390-1394.
MONTANI MSG, GRANATO M, CUOMO L, VALIA S, RENZO LD, D'ORAZI G, FAGGIONI A AND CIRONE M. 2016. High glucose and hyperglycemic sera from type 2 diabetic patients impair DC differentiation by inducing ROS and activating Wnt/ $\beta$-catenin and p38 MAPK. Biochim Biophys Acta 1862: 805-813.

MUOIO DM AND NEWGARD CB. 2008. Molecular and metabolic mechanisms of insulin resistance and $\beta$-cell failure in type 2 diabetes. Nature 9: 193-205.

OHLSSON L, ROSENQUIST A, REHFELD JF AND HARROD M. 2014. Postprandial effects on plasma lipids and satiety hormones from intake of liposomes made from fractionated oat oil: two randomized crossover studies. Food Nutr Res 58: 244-265.

PANI LN, NATHAN DM AND GRANT RW. 2008. Clinical predictors of disease progression and medication initiation in untreated patients with type 2 diabetes and A1C less than 7\%. Diabetes Care 31: 386-390.

PEPATO MT, MIGLIORINI RH, GOLDBERG AL AND KETTELHUT IC. 1996. Role of different proteolytic pathways in degradation of muscle protein from treptozotocin-diabetic rats. Am J Physiol 271(2): 340-347.

PIYA MK, TAHRANI AA AND BARNETT AH. 2010. Emerging Treatment Options for Type 2 Diabetes. Brit J Clinical Pharma 70(5): 631-644.

RANKIN MM AND KUSHNER JA. 2009. Adaptive betacell proliferation is severely restricted with advanced age. Diabetes 58: 1365-1372.

SALES ALC. 2011. Efeito de suplementação com aveia, linhaça, gergelim, semente de girassol e jatobá sobre parâmetros relacionados ao diabetes mellitus em ratos. Dissertação apresentada ao Programa de Pós-Graduação em Alimentos e Nutrição da Universidade Federal do Piauí, como requisito para obtenção do grau de Mestre em Alimentos e Nutrição, 97 p. (Unpublished).

SHEETZ MJ AND KING GL. 2002. Molecular understanding of hyperglycemias adverse effects for diabetic complications. The J Am Med Association 288: 25792588.

SOKAL RR AND ROHLF FJ. 1995. Biometry: the principles and practice of statistics in biological research. WH Freeman and Co, New York 392: 450 p.

SRINIVASAN BK, VISWANAD LA, KAUL CL AND RAMARAO P. 2005. Combination of high-fat diet-fed and low-dose streptozotocin-treated rat: A model for type 2 diabetes and pharmacological screening. Pharmacol Res 52: 313-320.

WHITE MF. 2002. IRS proteins and the common pathway to diabetes. Am J Physiol Endocrinol Metab 283(3): 413-422.

ZHANG JG, LIU Q, LIU ZL, LI L AND YI LT. 2015. Antihyperglycemic activity of Anoectochilus roxburghii polysaccharose in diabetic mice induced by high-fat diet and streptozotocin. J Ethnopharmacol 164: 180-185. 